\title{
Evidence for hypomotility in non-ulcer dyspepsia: a prospective multifactorial study
}

\author{
B Waldron, P T Cullen, R Kumar, D Smith, J Jankowski, D Hopwood, D Sutton, N Kennedy, \\ F C Campbell
}

\begin{abstract}
A prospective multifactorial study of symptoms and disturbance of gastrointestinal function has been undertaken in $\mathbf{5 0}$ patients with non-ulcer dyspepsia. Objective tests including solid meal gastric emptying studies, gastric acid secretion, E-HIDA scintiscan for enterogastric bile reflux, and hydrogen breath studies were carried out in all patients and validated against control data. Gastroscopy and biopsy were carried out in non-ulcer dyspepsia patients only. Non-ulcer dyspepsia patients were categorised on the basis of predominant symptoms as: dysmotility-like dyspepsia $(n=22)$; essential dyspepsia $(n=14)$, gastro-oesophageal reflux-like dyspepsia $(n=11)$; and ulcer-like dyspepsia $(n=3)$. In the total non-ulcer dyspepsia population, solid meal gastric emptying was delayed $\left(T_{50}\right.$ mean $($ SEM) $=102$ (6) minutes (patients) $v 64$ (6) minutes (controls), $(\mathbf{p}<0.01))$ and high incidences of gastritis $(n=26)$ and Helicobacter pyloridis infection $(n=18)$ were found. An inverse correlation was observed between solid meal gastric emptying and fasting peak acid output $(r=-0.4 ; p<0.01)$. Indeed gastric emptying was particularly prolonged in eight patients $\left(T_{50}\right.$ mean $(S E M)=139$ (15) minutes) with hypochlorhydria. In the non-ulcer dyspepsia population oral to caecal transit time of a solid meal was delayed (mean SEM $=302$ (14) minutes (patients) $v 244$ (12) minutes (controls) $(\mathbf{p}<\mathbf{0 . 0 1})$ ). Seven patients had a dual peak of breath hydrogen suggestive of small bowel bacterial overgrowth. No association was observed between symptoms and any of the objective abnormalities. This multifactorial study has shown that hypomotility, including gastroparesis and delayed small bowel transit, is common in non-ulcer dyspepsia and may be related to other disorders of gastrointestinal function. No relation between symptoms and disorders of function, however, has been shown.
\end{abstract}

Departments of Surgery,

Physics, Ninewells

Hospital and Medical

School, Dundee

B Waldron

PT Cullen

R Kumar

D Smith

J Jankowski

D Hopwood

D Sutton

N Kennedy

F C Campbell

Correspondence to:

Mr F C Campbell,

Department of Surgery,

Medical School, Dundee DDI

MSY.

Accepted for publication

23 April 1990 on the basis of suggestive symptoms, ${ }^{1}$ suppor evidence for a relation between symptoms and aetiology is lacking. Indeed, the pathogenesis of vious studies have identified individual abnormalities of gastrointestinal function, including delayed gastric emptying, ${ }^{23}$ gastritis with or without Helicobacter infection, ${ }^{+}$enterogastric bile reflux, ${ }^{5}$ and disorders of gastric acid secre- tion, ${ }^{67}$ a comprehensive approach has been lacking. Hence the relation between objective abnormalities within a single cohort of patients is unknown and no dominant aetiological factor has been identified.

This prospective study has evaluated and sought relations between symptoms and objective tests of gastric and small bowel function in a single cohort of patients with non-ulcer dyspepsia.

\section{Patients and methods}

DIAGNOSIS OF NON-ULCER DYSPEPSIA

Non-ulcer dyspepsia was diagnosed on the basis of persistent symptoms of abdominal pain, discomfort, bloating, or heartburn for a minimum of two months over at least two years, after exclusion of common organic disturbances (vide infra) on the basis of history, clinical examination, and a series of preliminary investigations. ${ }^{1}$

\section{EXCLUSION CRITERIA}

(1) Patients who gave a history of: recent abdominal surgery within one year of presentation; irritable bowel syndrome, which was defined as abdominal pain associated with predominant symptoms of diarrhoea or constipation $;^{8}$ and angina pectoris were excluded from the study.

(2) On clinical examination, abdominal mass or hernia constituted exclusion criteria.

(3) On investigation, peptic ulceration, upper gastrointestinal malignancy, gall stones, and gastro-oesophageal reflux were sought in all patients by endoscopy, abdominal ultrasound, and 24 hour ambulatory pH monitoring respectively. Oesophageal $\mathrm{pH}$ monitoring was assessed using a $\mathrm{pH}$ sensitive radiotelemetry pill suspended $5 \mathrm{~cm}$ above the manometrically determined high pressure zone.

Recording of $\mathrm{pH}$ data was collected by a portable microprocessor receiving unit (Aspen Medical Ltd, Ross-shire, Scotland). Computer based analysis determined the mean time of oesophageal $\mathrm{pH}$ less than 4 , the mean number and duration of reflux events in both the erect and supine positions, and also the cumulative acid exposure expressed as the percentage of data below each $\mathrm{pH}$ unit from 3 to 6 during the study. For each analysis method an individual record was considered abnormal (positive for reflux) if any one parameter was greater than 3 SD above the mean as determined from a control group consisting of 22 asymptomatic healthy volunteers. ${ }^{910}$

Patients who were free of the above conditions 
but had persistent symptoms were diagnosed as having non-ulcer dyspepsia and entered the study.

\section{STUDY PROTOCOL}

\section{Symptom assessment}

All patients had objective evaluation of seven symptoms: (i) abdominal pain, (ii) early satiety, (iii) bloating, (iv) heartburn, (v) regurgitation, (vi) loss of appetite, and (vii) nausea. These symptoms were evaluated by a standard self administered questionnaire which sought the presence of symptoms and scored severity by visual analogue scale. On the basis of predominant symptoms, patients with non-ulcer dyspepsia were assigned to one of five categories as outlined by the Working Party on the Management of Dyspepsia:

Dysmotility-like dyspepsia. Predominant symptoms of abdominal pain or discomfort, with typical onset after eating a meal and associated feeling of bloating, distension, early satiety, and nausea.

Ulcer-like dyspepsia. Epigastric pain with a tendency to waken the patient at night, and relief after eating small meals or antacids.

Gastro-oesophageal reflux-like dyspepsia. Predominant symptoms of epigastric or retrosternal heartburn, and regurgitation of acid or food.

Aerophagia. Abdominal air swallowing with typical symptoms of repetitive belching, bloating, and frequent dry swallowing.

Essential dyspepsia. Symptoms which do not fit into any of the categories described above and have no specific features on history or examination.

All patients then completed a series of gastrointestinal investigatons as follows.

\section{Gastroscopy and antral biopsies}

Gastroscopy was carried out after midazolam sedation. Gastroscopic appearances were categorised as normal or hyperaemic and were noted on a standard form. Two endoscopic biopsy specimens were taken from cranial and caudal aspects of the gastric antrum distal to the incisura and were fixed in formalin, stained with haematoxylin and eosin and with giemsa, and were then examined by a histopathologist. The diagnosis of gastritis was established on the basis of the polymorphonuclear infiltrate into the submucosa and mucosal hyperaemia with or without

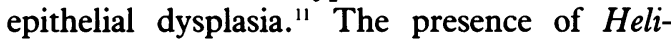
cobacter pyloridis organisms were sought histologically and their presence or absence was recorded.

\section{Evaluation of peak acid output}

Peak acid output was evaluated by the standard pentagastrin stimulation test. ${ }^{12}$ After an overnight fast gastric contents were aspirated continuously, first in the basal state and then after pentagastrin stimulation $(6 \mu \mathrm{g} / \mathrm{kg}$ body weight by subcutaneous injection). Acid secretion after pentagastrin stimulation was expressed as peak acid output in $\mathrm{mmol} /$ hour. The normal range in our laboratory, which has been previously defined in volunteers, lies between 6 and $40 \mathrm{mmol}_{\text {hour. }}{ }^{13}$

\section{Solid phase gastric emptying}

Solid phase gastric emptying was evaluated by scintigraphy using ${ }^{99 \mathrm{~m}} \mathrm{Tc}$ labelled scrambled egg. The meal was prepared by injecting $10 \mathrm{MBq}$ of ${ }^{99 m} \mathrm{Tc}$ stannous colloid into two beaten raw eggs and $30 \mathrm{ml}$ milk, which were then cooked until firm in consistency. This meal has a caloric value of 168 calories ( $13 \mathrm{~g}$ protein). After eating the meal, images were collected on a gamma camera (IGE 535 Maxicamera, International General Electric Medical Systems Ltd, Berks, England) which was interfaced to a mini computer (Nodecrest series V76, Byfleet, Surrey). Sequential anterior and posterior views were acquired at five minute intervals for the first hour and then at regular intervals until more than half the meal was perceived to have emptied from the stomach. The geometric mean of each image pair was generated to eliminate artifacts caused by movement of the meal through the stomach. ${ }^{14}$ The resulting series of images were used to evaluate the lag period before onset of emptying and the time for $50 \%$ emptying $\left(\mathrm{T}_{50}\right)$.

\section{Enterogastric bile reflux}

Enterogastric bile reflux was investigated in the fasting phase by ${ }^{99 m}$ Tc-E-HIDA biliary scintigraphy. After injection the isotope is cleared quickly from the blood pool by hepatobiliary function and secreted into the biliary system. Normally, the main hepatic ducts, common bile duct, cystic duct, gall bladder, duodenum, and small bowel are soon visualised. Enterogastric reflux of bile was defined as the demonstration of radioactivity visualised travelling in a retrograde fashion from the duodenum into the stomach..$^{15}$

\section{Hydrogen breath test}

This test was used to evaluate orocaecal transit time and also as a screening measure for small bowel bacterial overgrowth. Subjects were instructed to avoid non-absorbable dietary saccharides for 48 hours before the test. After an overnight fast, each subject was given a chlorhexidine mouth wash to eliminate oral bacteria, then breath samples $(20 \mathrm{ml})$ were taken using a modified Haldane Priestly tube, before and at 20 minute intervals after eating a meal. ${ }^{17}$ Baked beans contain indigestible oligosaccharides, which are not absorbed in the small bowel, but are rapidly fermented by anaerobic bacteria, generating hydrogen gas which diffuses rapidly into capillaries and is excreted in the breath..$^{18}$ Hydrogen concentration in parts per million (ppm) was evaluated using a GMI exhaled hydrogen monitor (GMI Instruments Ltd, Renfrew, Scotland). The standard meal comprised $200 \mathrm{~g}$ mashed potato, $100 \mathrm{~g}$ baked beans, and $25 \mathrm{ml}$ of water with $6.25 \mathrm{~g}$ glucose, which had a caloric value of $273 \mathrm{Kcal}$.

A dual peak of breath hydrogen was regarded as suggestive of small bowel bacterial overgrowth. ${ }^{19}$ In these circumstances, the first peak 
( $>10 \mathrm{ppm}$ ), which was usually detected within 30 minutes of meal ingestion and was sustained for at least three successive readings, represented hydrogen release due to fermentation by pathogenic small bowel bacteria and the second peak which occurred later represented fermentation by colonic bacteria after arrival of the substrate at the caecum. ${ }^{19}$

In the absence of a dual peak of breath hydrogen the orocaecal transit time was defined as the interval between meal ingestion and the demonstration of a single sustained rise of breath hydrogen concentration in excess of $10 \mathrm{ppm}$, sustained for at least three successive readings. ${ }^{20}$

\section{VOLUNTEER STUDIES}

Control values for solid meal gastric emptying time, orocaecal transit time by the hydrogen breath test, and percentage enterogastric bile reflux were determined by identical protocol in separate volunteer studies. The range of peak acid output has previously been validated in volunteers ${ }^{13}$ and was not therefore repeated.

\section{Control values}

Solid meal gastric emptying was assessed in 15 healthy volunteers (eight women, seven men) aged 24 to 70 years (mean (SEM) $=40$ (4) years).

Hydrogen breath test to determine orocaecal transit times was determined in 30 healthy volunteers (10 women, 20 men) aged 19 to 39 years $($ mean $(S E M)=28(2)$ years).

Enterogastric bile reflux was determined in 10 healthy volunteers (four women, six men) aged 21 to 74 years (mean $(S E M)=35$ (3) years).

On the basis of control values, abnormalities for each of these tests was defined as more than 2 SD outwith the mean.

\section{Tests of reproducibility}

Reproducibility studies of the hydrogen breath test were carried out in nine volunteers. This test was repeated on two occasions in five of the subjects and on three occasions in four subjects.

TABLE I Conditions in excluded patients

\begin{tabular}{lc}
\hline Condition & No of patients \\
\hline Gastro-oesophageal reflux & 12 \\
Gall stones & 3 \\
Duodenal ulcer & 1 \\
Oesophageal carcinoma & 1 \\
Symptom regression & 4 \\
Non-compliance & 7 \\
Total & 28 \\
\hline
\end{tabular}

TABLE II Individual symptoms and mean (SEM) severity scores in 50 non-ulcer dyspepsia patients

\begin{tabular}{llc}
\hline Symptoms & $\begin{array}{l}\text { Patients } \\
(\text { no })\end{array}$ & $\begin{array}{l}\text { Severity score } \\
(\text { scale 0-10) }\end{array}$ \\
\hline Abdominal pain & 50 & $4 \cdot 8(0 \cdot 3)$ \\
Abdominal bloating & 40 & $4 \cdot 5(0 \cdot 4)$ \\
Early satiety & 34 & $2 \cdot 8(0 \cdot 4)$ \\
Nausea & 32 & $3 \cdot 2(0 \cdot 4)$ \\
Heartburn & 24 & $2 \cdot 6(0 \cdot 4)$ \\
Regurgitation & 27 & $2 \cdot 0(0 \cdot 4)$ \\
Loss of appetite & 15 & $2 \cdot 1(0 \cdot 5)$ \\
Total symptom score/patient & & $22(1 \cdot 4)$ \\
No of symptoms/patient & & $4 \cdot 5(0 \cdot 2)$ \\
Length of history (months) & & $65(12)$ \\
\hline
\end{tabular}

Reproducibility tests of isotope based methods were avoided on the grounds of the requirement for repeated radiation exposure.

\section{ETHICAL APPROVAL}

The study protocol was approved by the Faculty of Medicine and Dentistry Ethics Committee, Ninewells Hospital. Each patient gave written, informed consent before participation.

\section{DATA ANALYSIS}

Because of the unequal number of patients and volunteers, analysis of gastric emptying and small bowel transit data was performed by the Mann-Whitney U test. The Pearson productmoment test of correlation was used to seek any relation between symptoms and objective tests, or any relation between objective tests themselves. Reproducibility was evaluated by one way analysis of variance and results expressed as a coefficient of variance.

\section{Results}

Twenty eight patients were ineligible for the study on the grounds of the exclusion criteria (Table I). Fifty patients then entered (36 women, 14 men) aged 18 to 75 years (mean $(\mathrm{SEM})=44$ (2) years).

\section{SYMPTOMS}

Individual symptoms and severity scores are shown in Table II. On the basis of predominant symptoms, patients were assigned to the following categories viz: dysmotility-like dyspepsia $(n=22)$, essential dyspepsia $(n=14)$; gastrooesophageal reflux-like dyspepsia $(n=11)$; ulcerlike dyspepsia $(n=3)$; and aerophagia $(n=0)$.

\section{OBJECTIVE TESTS}

\section{Volunteer studies}

Solid meal gastric emptying in volunteers $\left(T_{50}\right)$ was mean (SEM) 64 (6) minutes, with a range (mean ( 2 SD)) between 22 and 106 minutes.

Enterogastric bile reflux of $5 \%$ and $6 \%$ respectively of the administered isotope were seen in two of 10 volunteers. Hence, in this study, reflux of more than $5 \%$ was considered abnormal.

Hydrogen breath studies showed that the mean (SEM) orocaecal transit time in volunteers was 244 (12) minutes with a range (mean (2 SD)) between 125 and 355 minutes. The coefficient of variance for orocaecal transit times in volunteers was $0 \cdot 15$ (Fig 1). One volunteer had a dual peak of breath hydrogen during the study, suggestive of bacterial overgrowth.

\section{Patient studies}

Solid meal gastric emptying was slower in the non-ulcer dyspepsia population than in volunteers $\left(\mathrm{T}_{50}\right.$ mean $(\mathrm{SEM})=102$ (6) minutes (patients) $v 64(6)$ minutes (controls) $(\mathrm{p}<0.01)$ ). Gastric emptying delay, as previously defined, was identified in 21 patients (Fig 2). Histology of 


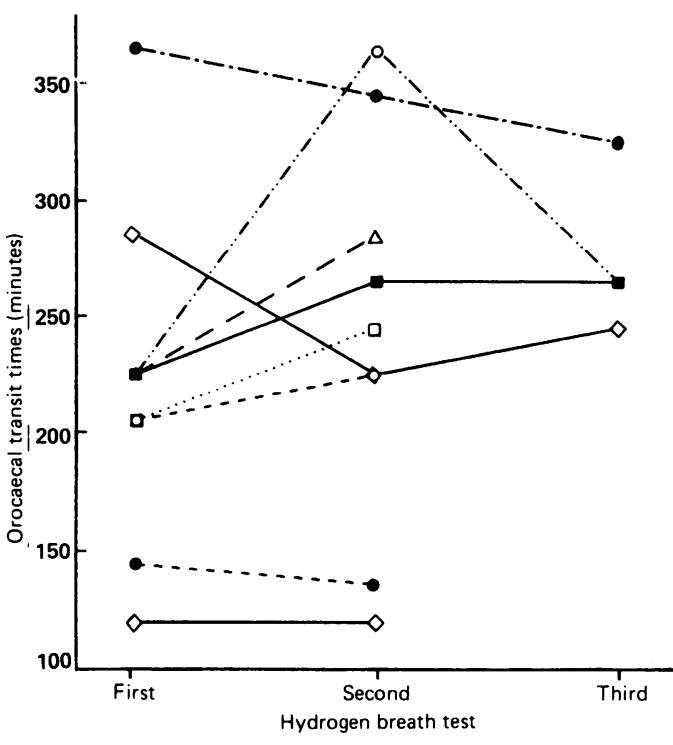

Figure 1: Reproducibility of the hydrogen breath test in nine volunteers. Individuals are identified by symbols. Coefficient of variance for within subject reproducibility $=15 \%$.

antral biopsy specimens showed inflammatory gastritis in 26 patients, of whom 18 had Helicobacter pyloridis infection. Eight patients had a peak acid output of less than $6 \mathrm{mmol} /$ hour after fasting pentagastrin stimulation, indicative of hypochlorhydria.

In the small bowel studies, orocaecal transit time was slower in patients than in controls (mean (SEM) 302 (14) minutes (patients) v 244 (12) minutes (controls) $(\mathrm{p}<0.01)$ ) (Fig 3). A dual peak of breath hydrogen suggestive of small bowel bacterial overgrowth was identified in seven patients. Enterogastric bile reflux of $>5 \%$, was observed in only one patient.

Multivariate analysis showed an inverse correlation between solid meal gastric emptying

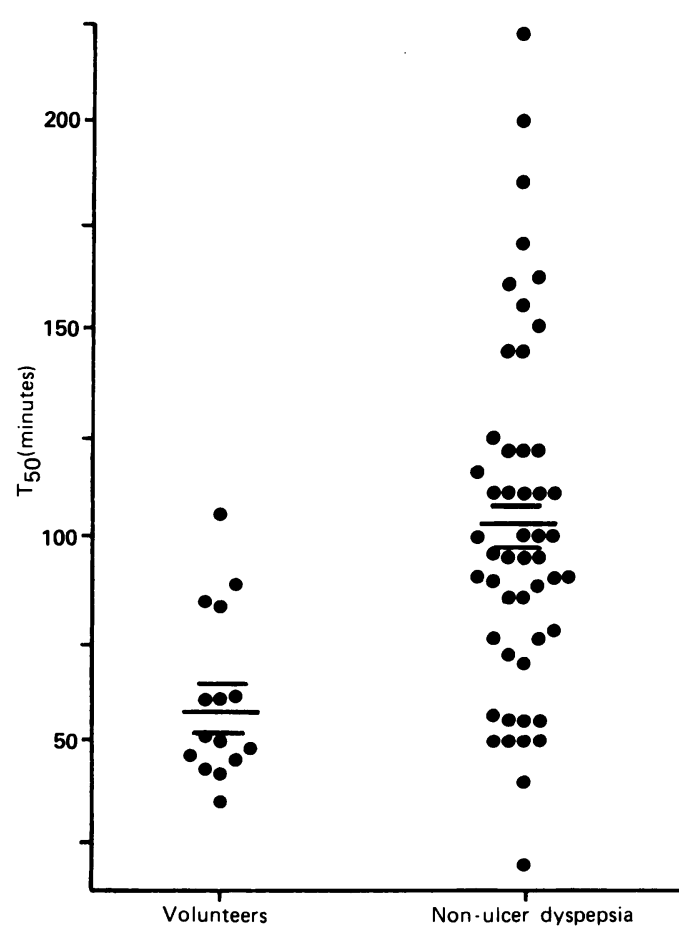

Figure 2: Solid meal gastric emptying times $\left(T_{50}\right) . T_{50}$ (mean (SEM)) 102 (6) minutes (patients) v 64 (6) minutes (controls); $p<0.01$ by Mann-Whitney $U$ test.

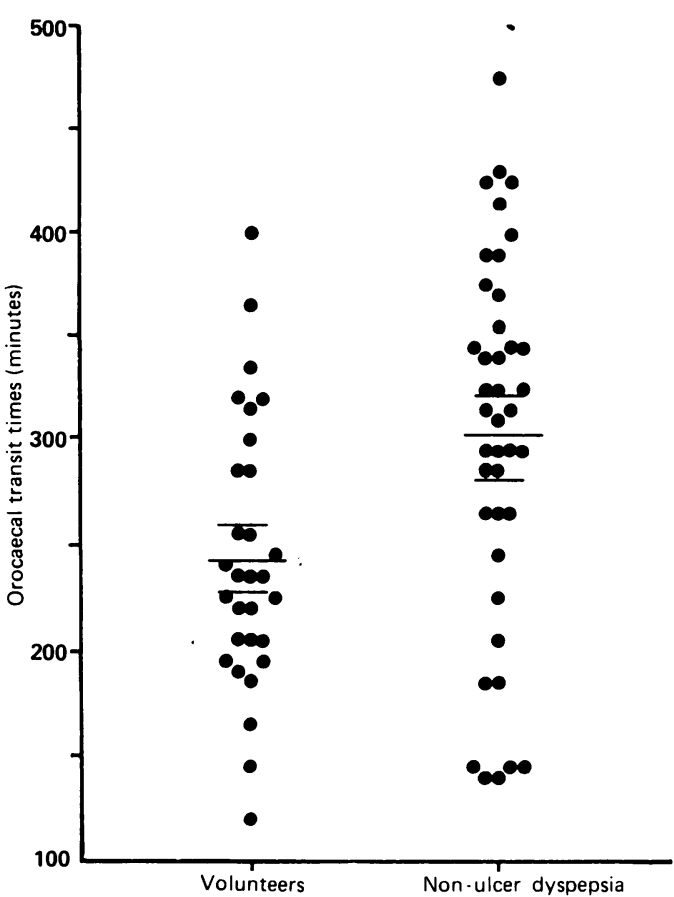

Figure 3: Orocaecal transit times: mean $(S E M)=302(14)$ minutes (patients) v 244 (12) minutes (controls); $p<0.01$ by Mann-Whitney U test.

time $\left(\mathrm{T}_{50}\right)$ and fasting peak acid output $(\mathrm{r}=-0 \cdot 4$; $\mathrm{p}<0.01$ ) (Fig 4) and a direct correlation between gastritis and Helicobacter pyloridis infection $(\mathrm{r}=0.62 ; \mathrm{p}<0.01)$. Age was directly related to gastritis only $(r=0.35 ; p<0.05)$. Gastric emptying delay was commonly present in association with other abnormalities although statistical significance was not observed (Table III).

No relation was found between individual symptoms, severe symptoms, or symptom categories and any of the objective abnormalities (Table IV).

Discussion

Non-ulcer dyspepsia is six to 10 times as

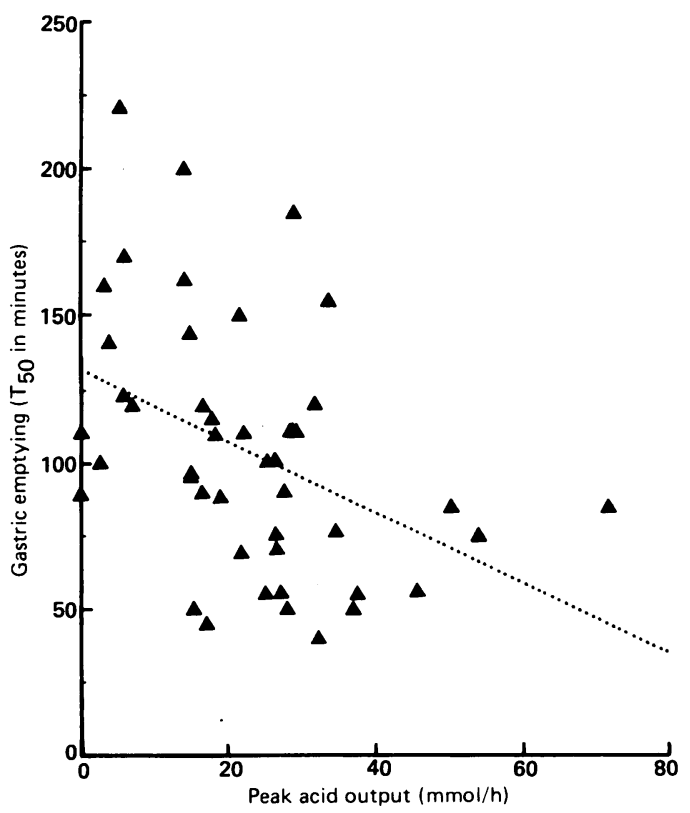

Figure 4: Relation between gastric emptying and peak acid output: $r=-0.4 ; p<0.01$ by the Pearson product moment test of correlation. 
TABLE III Relation of gastroparesis to other abnormalities in non-ulcer dyspepsia patients

\begin{tabular}{lll}
\hline & $\begin{array}{l}\text { No of } \\
\text { patients }\end{array}$ & $\begin{array}{l}\text { No with delayed } \\
\text { gastric emptying }\end{array}$ \\
\hline Gastritis & 26 & 10 \\
Helicobacter pylori & 18 & 9 \\
Delayed OCTT & 11 & 6 \\
Hypochlorhydria & 8 & 7 \\
Bacterial overgrowth & 7 & 2 \\
Enterogastric reflux & 1 & 1 \\
Total & 50 & 21 \\
\hline
\end{tabular}

OCTT $=$ orocaecal transit time.

common as peptic ulcer, is a major component of the gastroenterologist's workload, ${ }^{21}$ but has an obscure aetiology. To address this problem we firstly sought an accurate definition of non-ulcer dyspepsia, by careful exclusion of common organic abnormalities which are associated with similar symptoms, on the basis of clinical history, examination, and objective tests. While the distinction of non-ulcer dyspepsia from an ill defined disorder such as irritable bowel syndrome may be difficult, we sought discrimination on the basis of predominant symptoms of diarrhoea or constipation, as recommended by Manning et al. ${ }^{8}$ Diagnosis of the remaining exclusion criteria (recent abdominal surgery, angina, abdominal mass or hernia, peptic ulcer, gastrointestinal malignancy, gall stones, and gastro-oesophageal reflux) was straightforward, by the methods outlined. It is noteworthy, however, that few previous studies of non-ulcer dyspepsia have sought distinction of gastrooesophageal reflux, ${ }^{22}{ }^{23}$ which is surprising since this condition is well defined, ${ }^{2+}$ is accurately detected by 24 hour $\mathrm{pH}$ monitoring, ${ }^{9}$ and is effectively managed by appropriate treatment. Hence, in the present study, gastro-oesophageal reflux was regarded as distinct from non-ulcer dyspepsia and constituted the most common exclusion criterion $(n=12)$.

The patients entered into the study were a consecutive unselected series referred with chronic and persistent symptoms, with a mean duration of approximately five years. The age and sex distribution was similar to that reported by previous studies, there being a predominance of middle aged women. ${ }^{21}{ }^{25}$ The symptoms were diverse, and hence were categorised according to the recommendations of the Dyspepsia Working Party.' Dysmotility-like symptoms predominated.

Objective tests of gastrointestinal function were validated in volunteers before applying them to patients. In this study, the normal range in volunteers of solid meal gastric emptying,

TABLE IV Symptom categories and objective abnormalities in non-ulcer dyspepsia patients ${ }^{\star}$

\begin{tabular}{lllllll}
\hline $\begin{array}{l}\text { Dyspepsia } \\
\text { category }\end{array}$ & $\begin{array}{l}\text { Gastric } \\
\text { emptying }\end{array}$ & $P A O$ & Gastritis & Helicobacter & OCTT & Age \\
\hline $\begin{array}{l}\text { Dysmotility-like } \\
(\mathbf{n}=22)\end{array}$ & 0.83 & 0.49 & 0.76 & 0.85 & 0.97 & 0.09 \\
$\begin{array}{l}\text { GOR-like } \\
(\mathbf{n}=11)\end{array}$ & 0.55 & 0.59 & 0.32 & 0.91 & 0.61 & 0.11 \\
$\begin{array}{l}\text { Ulcer-like } \\
(\mathbf{n}=3)\end{array}$ & 0.49 & 0.38 & - & - & 0.75 & 0.98 \\
$\begin{array}{l}\text { Essential } \\
(\mathrm{n}=14)\end{array}$ & 0.66 & 0.42 & 0.21 & 0.76 & 0.53 & 0.67 \\
\hline
\end{tabular}

$\star$ Results expressed are $p$ values for each association by the Pearson product moment test for correlation. No significant association was observed.

$\mathrm{PAO}=$ peak acid output; OCTT $=$ orocaecal transit time; $\mathrm{GOR}=$ gastro-oesophageal reflux.
E-HIDA scintiscan, and oral to caecal transit times were similar to those reported previously. ${ }^{26-28}$ Similarly, the coefficient of variation (15\%) for oral to caecal transit studies by the hydrogen breath test is in accord with previous reports $^{29} 30$ and indicates an acceptable level of reproducibility. ${ }^{29}$ All patients then underwent gastrointestinal function studies as outlined.

In this study, gastroparesis was the commonest abnormality, with an equal incidence in both sexes and equally distributed among all age groups. Although gastroparesis was frequently present in association with other abnormalities, a statistically significant relation was observed only with gastric acid secretion. In all patients, an inverse correlation between solid meal gastric emptying time and fasting peak acid output after pentagastrin was observed. Indeed eight patients with hypochlorhydria had particularly prolonged solid meal gastric emptying. The association of these two abnormalities has been described previously,,$^{31}$ and by inference, indicates inhibition of both motor and secretory components of gastric function. This functional impairment is unlikely to be an age related phenomenon since no association was observed between gastroparesis or low acid output with age. The incidence of Helicobacter pyloridis infection and gastritis in this study is in accord with that reported previously in non-ulcer dyspepsia, ${ }^{+}$ and the incidence of each is greater than that seen in asymptomatic control subjects. ${ }^{32}$ As would be expected, a significant direct relation was observed between gastritis and Helicobacter infection. It is unlikely, however, that these factors alone or in combination could be responsible for the gastric functional impairment noted above, since gastric emptying times and secretory response to pentagastrin in this study were unrelated to the presence or absence of gastritis or Helicobacter pyloridis. Hence, we have been unable to define predisposing causes for the related gastric motor and secretory disturbances which have been found in this study of non-ulcer dyspepsia.

The orocaecal transit time of a standard solid meal, as assessed by the hydrogen breath test, had an acceptable level of reproducibility and was significantly prolonged in non-ulcer dyspepsia patients. This abnormality was observed in association with $(n=6)$ or independent of $(n=5)$ gastroparesis, which suggests a genuine independent delay in small bowel transit and hypomotility.

The presence of small bowel bacterial overgrowth was suggested by detection of a dual peak of breath hydrogen excretion in seven patients, of whom three had gastroparesis or hypochlorhydria, or both, which could potentially represent predisposing factors. Diagnosis of small bowel bacterial overgrowth by this method has previously been shown to have a sensitivity ranging between $36 \%{ }^{33}$ and $93 \%{ }^{34}$ and a specificity between $75 \%{ }^{35}$ and $100 \% .{ }^{36}$ In the present study, however, a positive result was obtained in one volunteer, which confirms the lack of absolute specificity for this test. We have not carried out any validation studies against jejunal aspirate culture and hence our data regarding bacterial overgrowth should be regarded as sug- 
gestive rather than conclusive. Hyperacidity was uncommon in this study, which may go some way to explaining the poor results in trials of acid reducing agents. ${ }^{22}$ Similarly, enterogastric bile reflux was uncommon in this study.

In this study we found no correlation between any of the objective tests and any of the individual symptoms, severe symptoms, or symptom categories as defined according to the recommendations of the Dyspepsia Working Party. ${ }^{1}$ Hence, in this respect, our findings are in accord with those of Malegalada et al, who reported a lack of correlation between symptoms and gastrointestinal motility disorders in patients with functional abdominal pain, ${ }^{37}$ and also with Jian et al, who found no relation between symptoms and objective gastric stasis in non-ulcer dyspepsia. ${ }^{38}$

In conclusion, this prospective multifactorial study has identified a heterogeneous spectrum of gastrointestinal dysfunction in non-ulcer dyspepsia. However, hypomotility in the form of delayed gastric emptying, or small bowel transit, or both, seems to dominate.

This study was supported by a research grant from Jansssen Pharmaceutical Ltd, UK. The authors gratefully thank Mr S Ogsten for his advice on statistical analyses.

1 Colin-Jones DG. Management of dyspepsia: report of a working party. Lancet 1988; i: 576-9.

2 Narducci F, Bassoti G, Granata MT et al. Functional dyspepsia and chronic idiopathic gastric stasis: role of endogenous opiates. Arch Intern Med 1986; 146: 716-20.

3 Urbain JC, Siegal JA, Debie NC, Pauwels SP. Effect of cisapride on gastric emptying in dyspeptic patients. Dig Dis Sci 1988; 33: 779-83.

4 Rokkas T, Pursey C, Uzoechina E et al. Campylobacter pylori and non ulcer dyspepsia. Am $\mathcal{F}$ Gastroenterol 1987; 82 $1149-52$.

5 Johnson AG, Harding Rains AJ. The relationship between biochemical and radiological evidence of pyloric reflux in patients with flatulent dyspepsia. Br F Surg 1969; 56: 384.

6 Joffe SN. Relevance of duodenitis to non ulcer dyspepsia and peptic ulceration. Scand F Gastroenterol 1981; 17 (suppl 79): 88-97.

7 Christiansen J, Aagaard P, Koudal G. Truncal vagotomy and drainage in the treatment of ulcer like dyspepsia without drainage in the treatment of ulcer like
ulcer. Acta Chir Scand 1973; 139: 173-5.

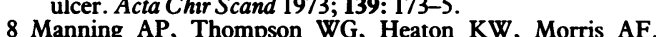
Towards positive diagnosis of the irritable bowel. $B M \mathcal{J}$ 1978; $2: 653-4$

9 Vitale GC, Cheadle WG, Sadek S, Michel ME, Cuschieri A. Computerized 24-hour ambulatory esophageal $\mathrm{pH}$ monitoring and esophagogastroduodenoscopy in the reflux patient. Ann Surg 1984; 200: 724-8.

10 Vitale GC, Sadek S, Tulley FM, et al. Computerized 24-hour oesophageal $\mathrm{pH}$ monitoring: a new ambulatory technique using radiotelemetry. $\mathcal{F}$ Lab Clin Med 1985; 105: 686-93.

11 Whitehead R, Truelove SC, Gear MNL, The histologica diagnosis of chronic gastritis in fiberoptic gastroscope biopsy specimens. F Clin Pathol 1972; 25: 1-11.

12 Wormsley KG, Mahony MP, Kay G. Gastric response to subcutaneous injection of a gastrin-like pentapeptide. Gut 1976; 8: 475-81.
13 Kirkpatrick JR, Lawrie JH, Forrest APM, Campbell H. The short pentagastrin test in the investigation of gastric disease. Gut 1969; 10: 760-2.

14 Tothill P, McLoughlin GP, Heading RC. Techniques and errors in scintigraphic measurements of gastric emptying. f Nuc Med 1978; 19: 256-61.

15 Kennedy NSJ, Campbell FC, Cullen PT, Sutton DG, Millar BW, Cuschieri A. Gallbladder function and fasting enterogastric bile reflux. Nuc Med Comm 1989; 10: 193-8.

16 Mackie CR, Wisbey ML, Cuschieri A. Milk ${ }^{\text {gam }}$ Tc-EHIDA test for enterogastric bile reflux. Br $\mathcal{F}$ Surg 1982; 69: 101-4

17 Metz G, Gassull MA, Leeds AR, Blendis LM, Jenkins DJA. A simple method of measuring breath hydrogen in carbohydrate malabsorption by end expiratory sampling. Clinical Science and Molecular Medicine 1976; 50: 237-40.

18 Levitt MD. Production and excretion of hydrogen gas in man NEngl F Med 1969; 281: 122-7.

19 Rhodes JM, Middleton P, Jewell DP. The lactulose hydrogen breath test as a diagnostic test for small bowel bacterial overgrowth. Scand f Gastroenterol 1979; 14: 333-6.

20 Campbell FC, Cuschieri A. Critical rise of breath hydrogen in evaluation of intestinal transit. Gut $1984 ; 21$ : A1270.

21 Nyren O, Adami HO, Gustavsson S, Loof L, Nyberg A. Socia and economic effects of non ulcer dyspepsia. Scand f Gastroenterol 1985; 20 (suppl 109): 41-5.

22 Nyren O, Adami HO, Bates S, et al. Absence of therapeutic benefit from antacids or cimetidine in non ulcer dyspepsia. NEnglF Med 1986; 314: 339-43.

23 Taha AS, Boothman P, Holland P, et al. Gastric mucosal prostaglandin synthesis in the presence of Campylobacter pylori in patients with gastric ulcer and non ulcer dyspepsia. Am $\mathcal{F}$ Gastroenterol 1990; 85: 47-50.

24 Talley NJ, Piper DW. The association between non ulcer dyspepsia and other gastrointestinal disorders. Scand f Gastroenterol 1985; 20: 896-900.

25 Krag E. Non ulcer dyspepsia introduction: epidemiological data. Scand f Gastroenterol 1982; 17 (suppl 79): 6-8.

26 Siegel JA, Urbain J-L, Adler LP, et al. Biphasic nature of gastric emptying. Gut 1988; 29: 85-9.

27 Shaffer EA, McOrmond P, Duggan H. Quantitative cholescintigraphy: assessment of gallbladder filling and emptying and duodenogastric reflux. Gastroenterology 1980; 79: 899-906.

28 Cann PA, Read NW, Hobson N, Holdsworth CD. Irritable bowel syndrome: relationship of disorders in transit of a single solid meal to symptom patterns. Gut 1983; 24: 405-11.

29 Bond HJ, Levitt MD. Investigation of small bowel transit time in man utilizing pulmonary hydrogen $\left(\mathrm{H}_{2}\right)$ measurements. f L ab Clin Med 1975; 85: 546-55.

30 Corbett CL, Thomas S, Read NW, Hobson N, Bergman I, Holdsworth CD. Electrochemical detector for hydrogen boldsworth CD. Electrochemical detector for hydrogen time in normal subjects and patients with irritable bowel time in normal subjects and patien

31 Rees WDW, Miller LJ, Malagelada J-R. Dyspepsia, antral motor dysfunction and gastric stasis of solids. Am f Gastroenterol 1980; 78: 360-5.

32 Barthel JS, Westblom UT, Havey AD, Gonzalez F, Everett DE. Gastritis and Campylobacter pylori in healthy asymptomatic volunteers. Arch Intern Med 1988; 148: 1149-51.

33 Taylor RH, Avgerinos A, Taylor AJ, Hill MJ, Misiewicz JJ. Bacterial colonisation of the jejunum: an evaluation of five diagnostic tests. Gut 1981; 22: A442-3.

34 Kerlin P, Wong L. Breath hydrogen testing in bacterial overgrowth of the small intestine. Gastroenterology $1988 ; 95$; overgrow.

35 O'Connor MP, Healy M, Kehely A, Keane CT, O'Moore RR, Weir DG. $\mathrm{H}_{2}$ or ${ }^{14} \mathrm{C}$-breath tests in the diagnosis of small intestinal bacterial overgrowth? Gastroenterology 1987; 92: 1557

36 Metz G, Gassul MA, Draser BS, Jenkins DJA, Blendis LM. Breath-hydrogen test for small-intestinal bacterial colonisation. Lancet 1976; 1: 668-9.

37 Malegaleda J-R, Stanghellini V. Manometric evaluation of functional upper gut symptoms. Gastroenterology 1985; 88: $1223-31$.

38 Jian R, Ducrot F, Ruskone A, et al. Symptomatic, radionuclide and therapeutic assessment of chronic idiopathic dyspepsia: A double-blind placebo-controlled evaluation of cisapride. Dig Dis Sci 1989; 34: 657-64. 